\title{
Conservative approach for the treatment of urethral prolapse in children: case report and literature review of 278 pediatric cases
}

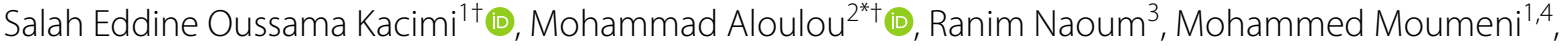 \\ Abdallah Kaddour ${ }^{1,4}$ and Mohammed Said ElSheemy ${ }^{5}$
}

\begin{abstract}
Background: Urethral prolapse (UP) is a rare, benign condition that often goes misdiagnosed and mistreated. It consists of the eversion of the distal urethral mucosa through the outer urethral meatus, leading to vascular obstruction and prolapsed tissue edema, which aggravates the prolapse. Although many review articles were reported on this condition, none of them focused on the conservative approach nor targeted the pediatric population. In this paper, we present successful medical management of UP in a 13-month-old Caucasian female and perform an extensive review of the literature to include articles that reported a conservative approach in patients under 18-years-old. We also suggested a practical algorithm for both diagnosis and management of this condition.
\end{abstract}

Case presentation: A 13-month-old Caucasian white female was presented with a urinary tract infection and vaginal bleeding. Genital examination showed a hyperemic donut-shaped mass covering the urinary meatus, of $0.7 \mathrm{~cm}$ diameter, with an actively bleeding open center. After confirming the diagnosis of UP with catheterization, a conservative approach was decided; antibiotics associated with topical corticosteroids including betamethasone $1 \% \mathrm{cream}$. The first-week outcome showed regression of the prolapsed tissue and the examination after four months showed normal vaginal mucosa with no evidence of relapse.

Conclusions: 20 studies were retained after PubMed search with a total of 278 female patients aged between 1 month and 15 years old. The main reasons for referral were vaginal bleeding and mass, urinary symptoms followed by sexual abuse. Non-surgical treatment was tried for 162 patients. 53 of them were successfully managed, while 92 reported unsuccessful outcomes. The conservative approach was successful in 19\% of all patients and raised to $32.7 \%$ in the portion of children selected for the initial conservative approach. Even though this review showed good results with medical treatment in children with UP, additional comparative studies are required to evaluate the effectiveness of conservative treatment in comparison with surgical interventions. In addition, Long-term follow-up is required as recurrence was reported up to 2 years following conservative treatment.

Keywords: Pediatric, Urethral prolapse, Vaginal bleeding, Conservative approach, Urethral disease

*Correspondence: dr.mohammad.aloulou.99@gmail.com tSalah Eddine Oussama Kacimi and Mohammad Aloulou have contributed equally to this work

${ }^{2}$ Faculty of Medicine, University of Aleppo, Aleppo, Syria Full list of author information is available at the end of the article

\section{Background}

Urethral prolapse (UP) is a rare, benign condition, which may have deleterious consequences if not treated properly [1-3]. It consists of the eversion of the distal urethral mucosa through the outer urethral meatus, leading to vascular obstruction and prolapsed tissue edema, which aggravates the prolapse [3-6]. Most of the reported 
cases were seen in the pediatric population, with an estimated prevalence of 1:3000 children [1]. Furthermore, the condition primarily affects prepubertal black girls or postmenopausal white women $[1,2,4,5]$, with a higher incidence in girls of African descent $[4,6]$.

Although many literature reviews were reported on this condition, none of them focused on the pediatric population. Herein, we present successful medical management of UP in a 13-month-old Caucasian female and perform a comprehensive review aiming to give an overview on the conservative approaches in managing this condition, with a main focus on the pediatric population.

\section{Materials and methods}

Two reviewers comprehensively searched MEDLINE through PubMed from 1999 till September 2020 using the following search strategy; (("urethra"[Title/Abstract]) OR ("urethral"[Title/Abstract])) AND (((("prolapse"[Title/ Abstract]) OR ("prolapsus"[Title/Abstract])) OR ("bulge"[Title/Abstract])) OR ("eversion"[Title/ Abstract])) OR ("protrusion"[Title/Abstract])) to retrieve articles reporting UP cases.

Because this paper focused on the conservative (nonsurgical) treatment of UP in the pediatric population, only articles that reported a conservative approach in patients under 18-years-old were included. Therefore, articles reporting surgical treatment alone were excluded. Furthermore, review articles, book chapters, studies performed on animal models, and in vitro studies were excluded from this review. No restrictions were applied regarding the language. English and French articles were considered for full-text screening directly while articles in other languages were translated using Google Translate first. The study flow diagram is illustrated in Fig. 1. In addition, after obtaining written consent from the parents of the patient, we reported a case of UP in a 13-month-old female that was successfully treated using a conservative approach.

\section{Results}

\subsection{Case presentation}

A 13-month-old Caucasian white female infant was admitted to our department complaining of urinary tract infection and vaginal bleeding. She had no history of trauma or instrument-induced injury to the vagina. However, she had two episodes of urinary tract infection (UTI). The last one occurred one month prior to the presentation and was successfully treated with antibiotics.

Physical and abdominal examinations were normal. Vital signs were within normal limits with no fever. Genital examination showed a hyperemic donut-shaped mass covering the urinary meatus, of $0.7 \mathrm{~cm}$ diameter, with an actively bleeding open center. The vaginal mucosa

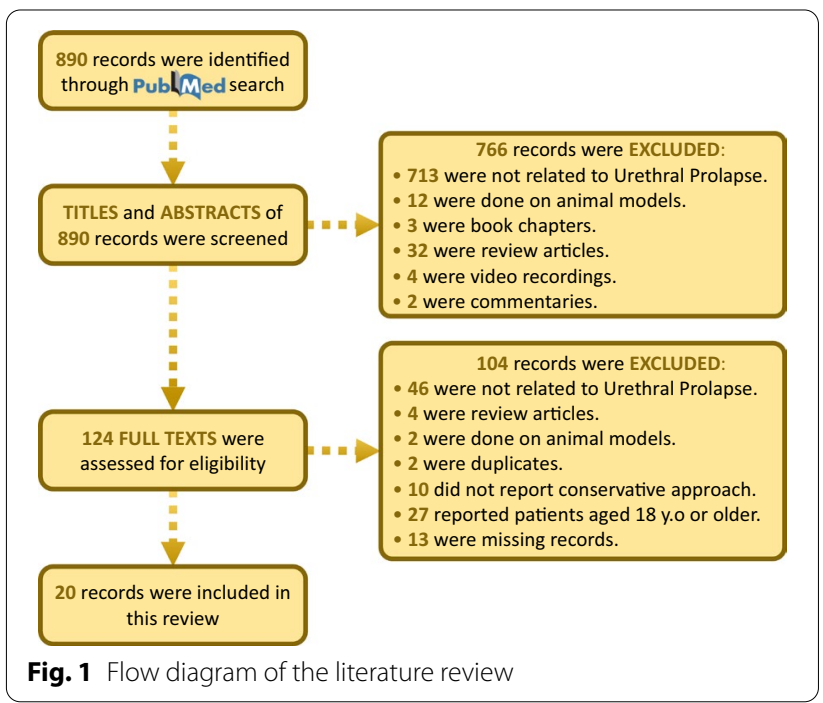

surrounding the mass was normal and the hymen was intact (Fig. 2a). Complete blood count and additional lab findings revealed elevated platelets, lymphocytes, and C reactive protein. Urine samples were collected for microbiological analysis and culture. Treatment of UTI was started by using a combination of two antibiotics; cefotaxime $100 \mathrm{mg} / \mathrm{kg}$ per day for 10 days and gentamicin $5 \mathrm{mg} / \mathrm{kg}$ for 3 days. An urgent abdominopelvic ultrasound imaging showed no sonographic abnormalities in the kidneys, bladder, or uterus. The diagnosis of UP was established and a 12 French size catheter was placed in the open center of the mass (Fig. 2b), urine output from the center of the protrusion confirmed the diagnosis of UP. A cystoscopy was performed and excluded potential ureterocele.

A conservative approach was decided. The empirical antibiotic treatment was maintained later after receiving the urine culture isolating Escherichia Coli. The antibiotic therapy was associated with topical corticosteroids including betamethasone $1 \%$ cream 2 times daily for 10 days applied on the prolapsed tissue. Topical estrogen wasn't prescribed as this drug was not available in the local market. The first-week outcome showed regression of the prolapsed tissue (Fig. 2c), and the patient was discharged with a scheduled follow-up appointment. After four months, the patient was seen in the outpatient clinic, and the examination showed normal vaginal mucosa with no evidence of relapse. The mother denied any symptoms of urinary infection or bleeding over that period.

\section{Review of the literature}

The initial search identified 890 articles, of which 124 were retained for full-text screening after examination of titles and abstracts. After a full-text review, we excluded 

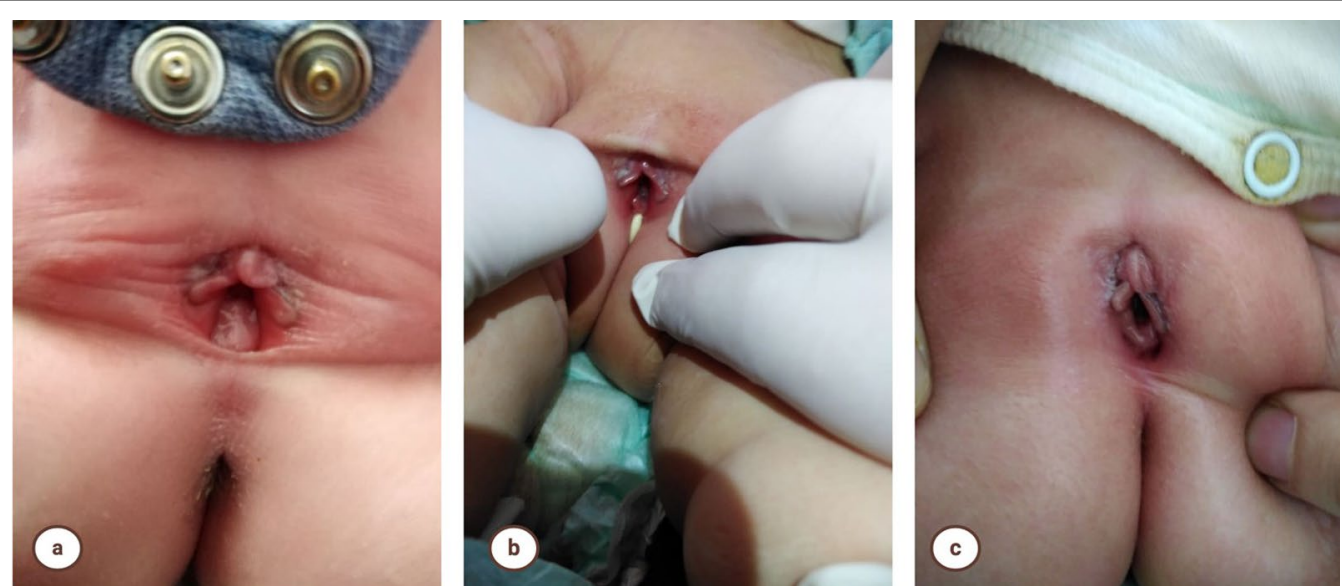

Fig. 2 a The appearance of the prolapsed tissue on physical examination, $\mathbf{b}$ urethral catheterization of the prolapsed urethra, $\mathbf{c}$ the healthy appearance of the urethral meatus after the resolution of the prolapse

104 studies. The total number of articles identified in these steps and reasons for exclusion are shown in Fig. 1. Out of the 20 studies retained, 11 were case series [ 1 , $3,5-13]$ and 9 were case reports[2, 4, 14-20]. Included studies reported non-surgical treatment as a first-line option in $162(58.3 \%)$ patients and surgical approach in $116(41.7 \%)$ patients as the first-line arm for management of UP in 278 patients (Fig. 3). All patients were females aging between 1 month and 15 years old across the included studies. Among the 142 patients with black skin color, 2 infants were Afro-Caribbean, 65 were African and 1 was African-American. On the other hand, 5 patients were of white skin color with 3 infants being Caucasians (Table 1).
The main reasons for referral were vaginal bleeding reported in 154 (55.4\%) patients, vaginal mass in 67 (24.1\%) patients, followed by urinary symptoms (including dysuria, urodynia, and hematuria), and urethral mass in $16(5.8 \%)$ patients for each. Sexual abuse was suspected in $8(2.9 \%)$ cases. Other reported symptoms included mucoid discharge (leucorrhea), trauma, congenital malformation, and constipation. Yet, 13 patients were asymptomatic. The main reasons for referral are illustrated in Fig. 4. Medical and surgical history was reported in 15 articles [1-6, 9, 12-19], varying from no remarkable history to urinary tract infection, malnutrition, cough, respiratory infection, asthma, vulvitis, diarrhea, constipation, hernia, and trauma.

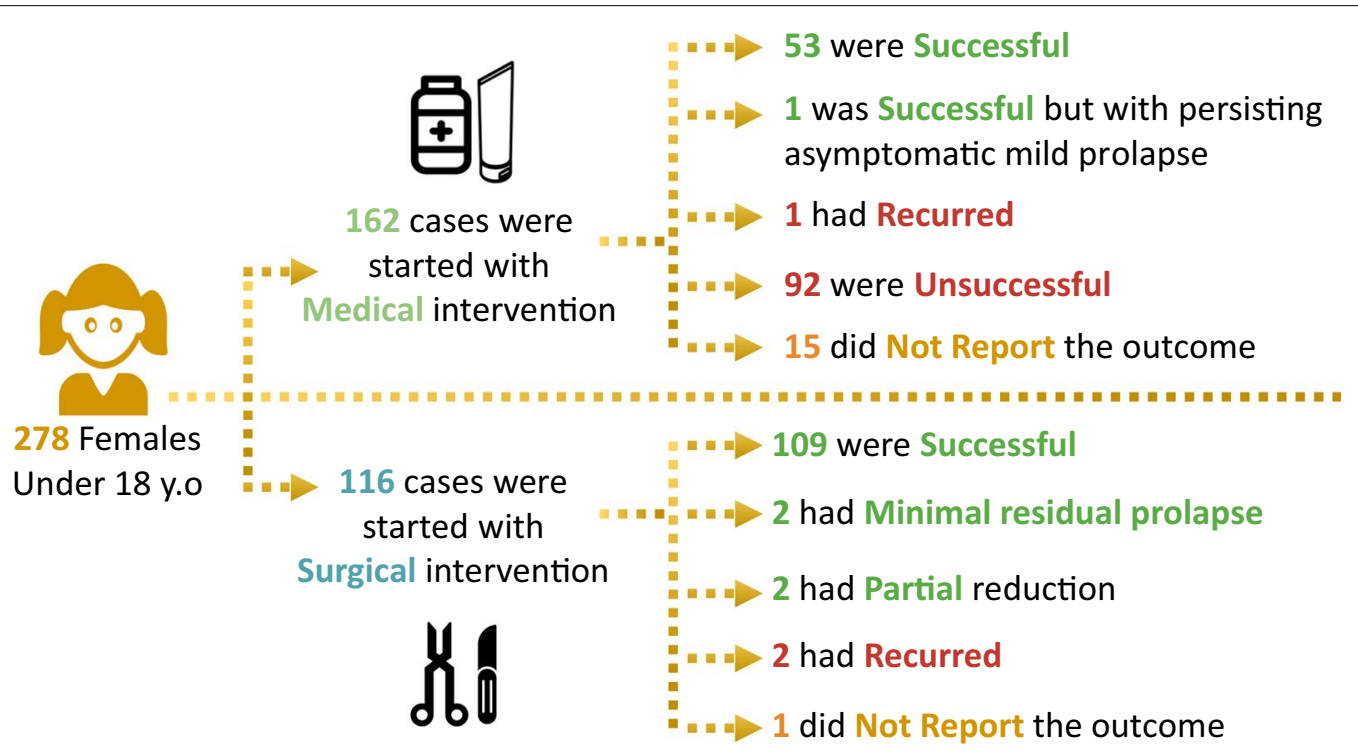

Fig. 3 Treatment outcomes of 278 children with urethral prolapse 


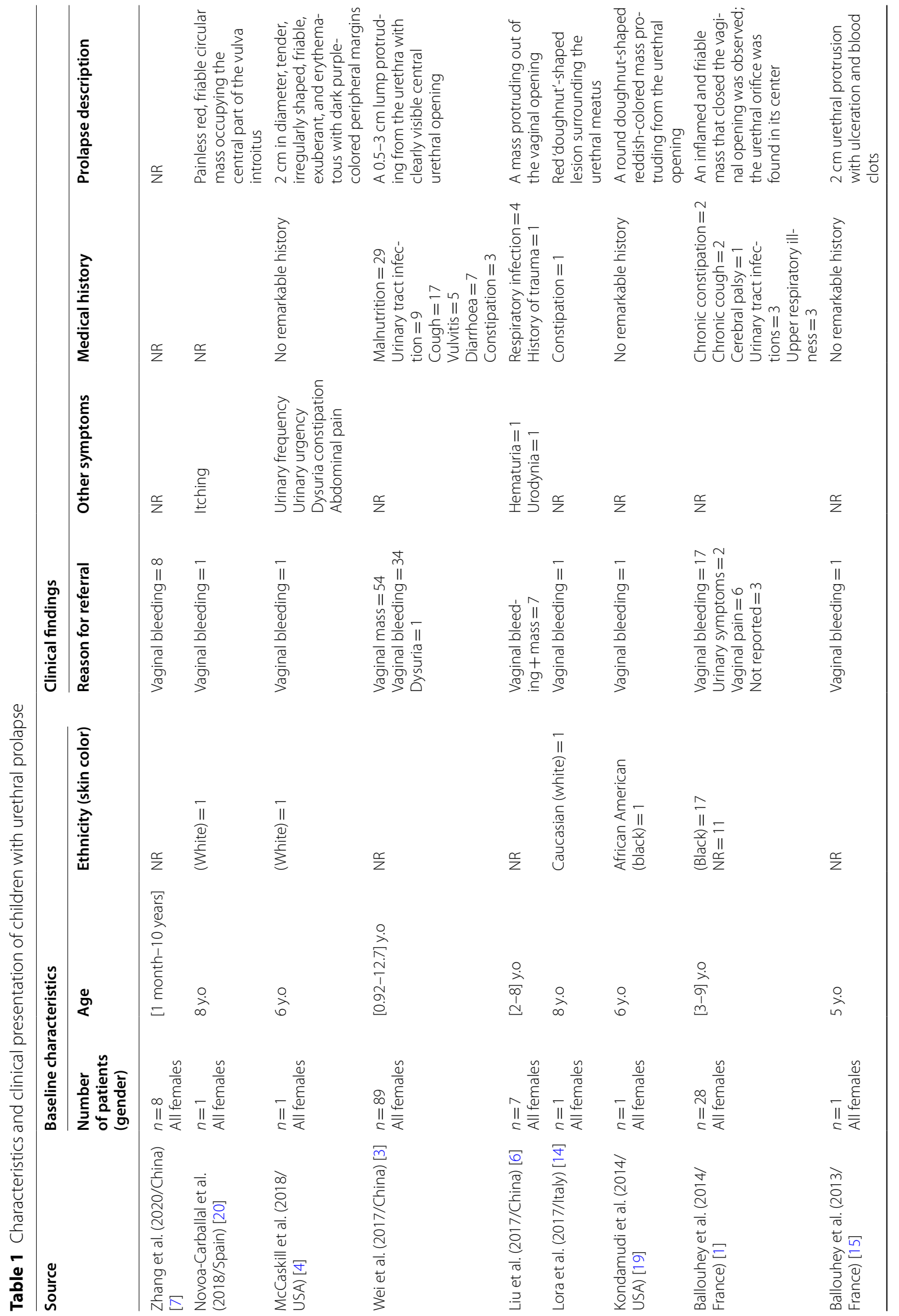




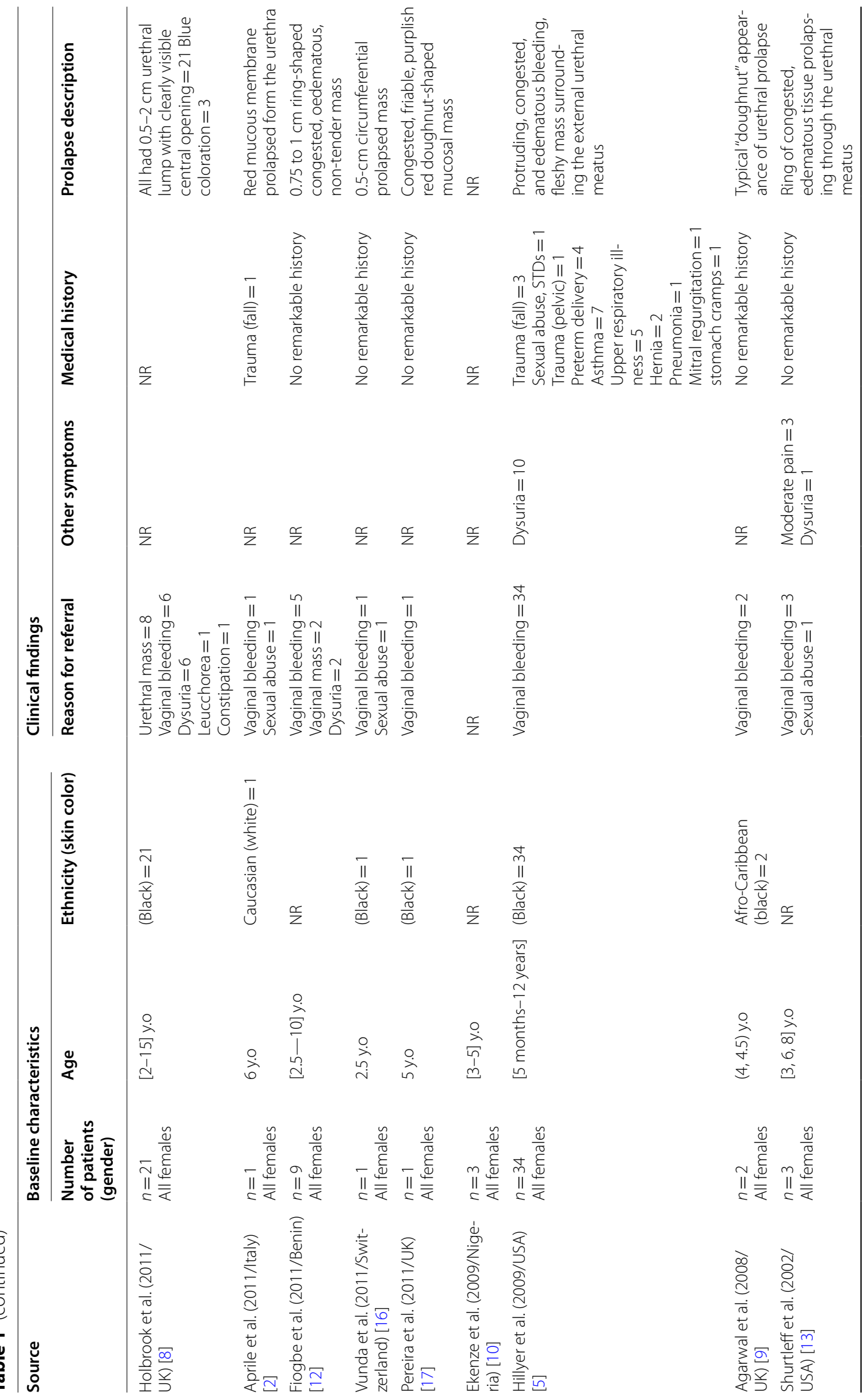




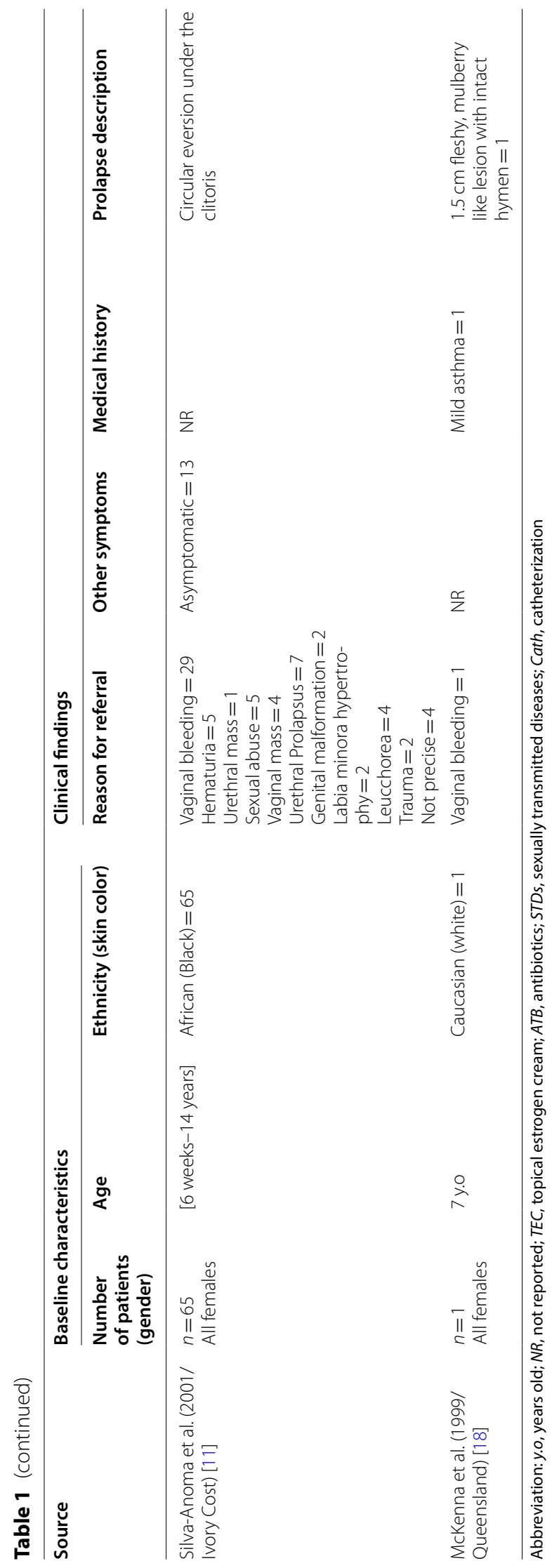




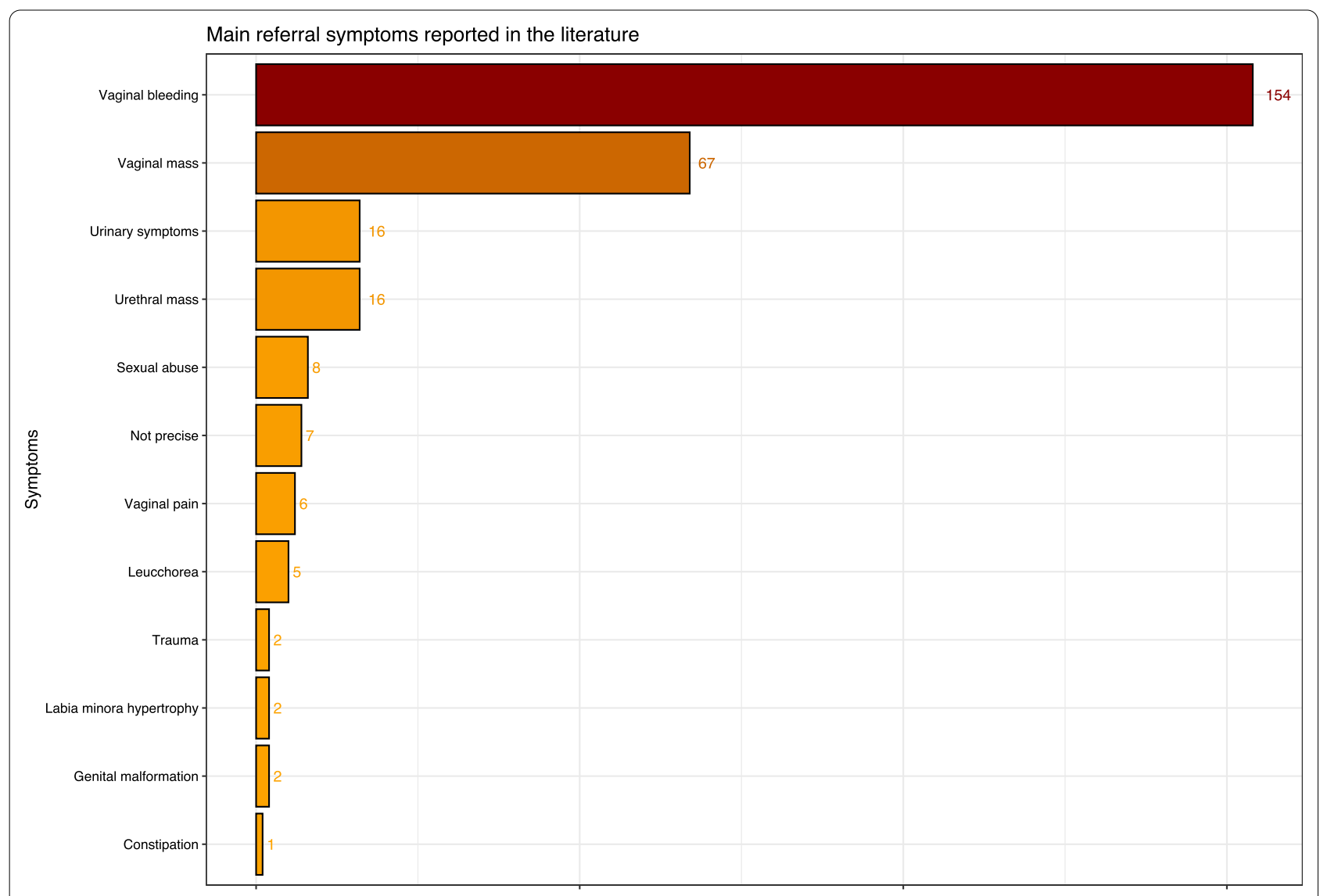

Fig. 4 Bar-plot of the main referral symptoms reported in the literature for children with urethral prolapse

Of the 278 infants, $162(58.3 \%)$ cases were started with conservative treatment as a first-line option among whom 53 (32.7\%) were successfully managed, while 92 $(56.8 \%)$ reported unsuccessful outcomes. Additionally, one case $(0.6 \%)$ reported a mild degree of persisting asymptomatic prolapse during follow-up [20], and another one $(0.6 \%)$ reported recurrence after 2 years which required surgery [2]. The outcomes were not reported in 15 (9.3\%) patients. Surprisingly, one study reported successful management of UP in a 6-year-old girl with only a few days of home rest [2], yet the girl had recurrence after 2 years and required surgery.

Conservative treatments consisted of topical estrogen cream (TEC), sitz bath, and local antiseptic in most of the cases, while local applications of antibiotics and topical steroids (TS) were less prescribed. Antispasmodic drugs, manipulative reduction, and catheterization were also reported. On the other hand, surgical treatment consisted mostly of surgical excision over a Foley catheter followed by mucosal sutures. Other techniques such as four-quadrant excision and the Doria technique were also noted. Surgery was indicated as the first-line option in 116 (41.7\%) patients and whenever there were a complicated prolapse or failure of medical treatment in 91 (32.7\%) patients. Across the included studies, follow-up duration was reported only in 14 articles $[1-4,6,10-18]$ and ranged from 2 weeks to 5 years. All detailed treatment, its indications, outcomes, and follow-up duration are reported in Table 2 .

\section{Discussion}

Urethral prolapse primarily affects prepubertal black girls or postmenopausal white women $[1,2,4,5]$, with a higher incidence in girls of African descent $[4,6]$. On the contrary to this usual presentation, our case reported prolapse in a white Caucasian girl.

The pathophysiology of UP is still uncertain. Estrogen deficiency remains the main hypothesis and explains the higher incidence of urethral prolapse in prepubertal and postmenopausal periods. Other supposed factors include urethral trauma and catheterization, and infection. Some studies confirmed the presence of marked mucosal eversion and vascular congestion. Another possible risk factor is high intra-abdominal pressure associated with weak collagen as many patients reported family history of hernia and vaginal prolapse $[8,21-23]$. 


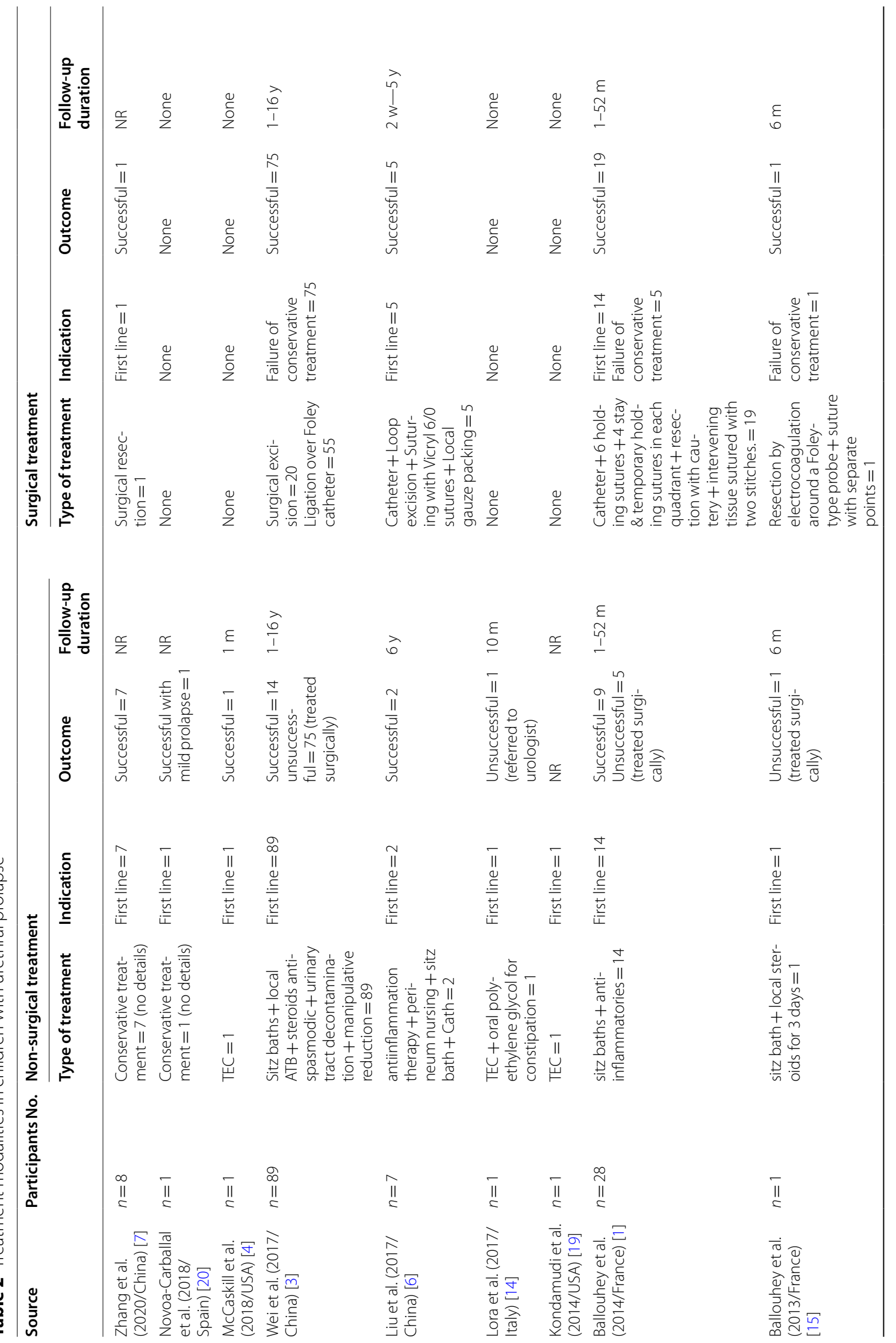




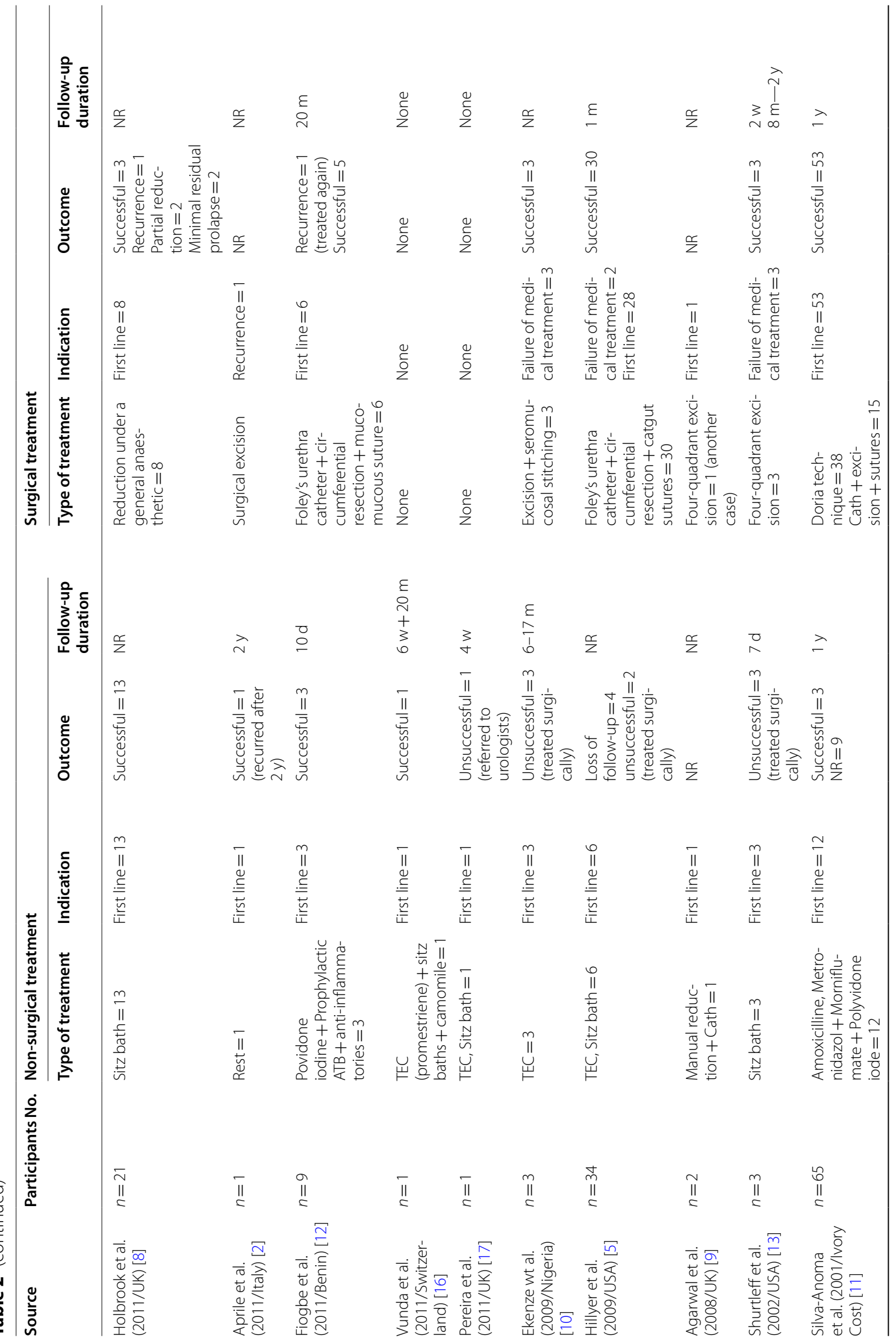




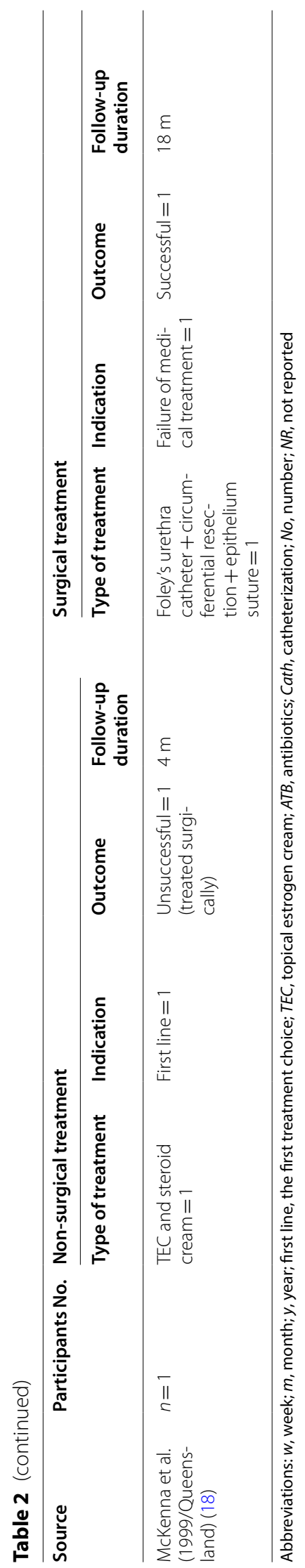




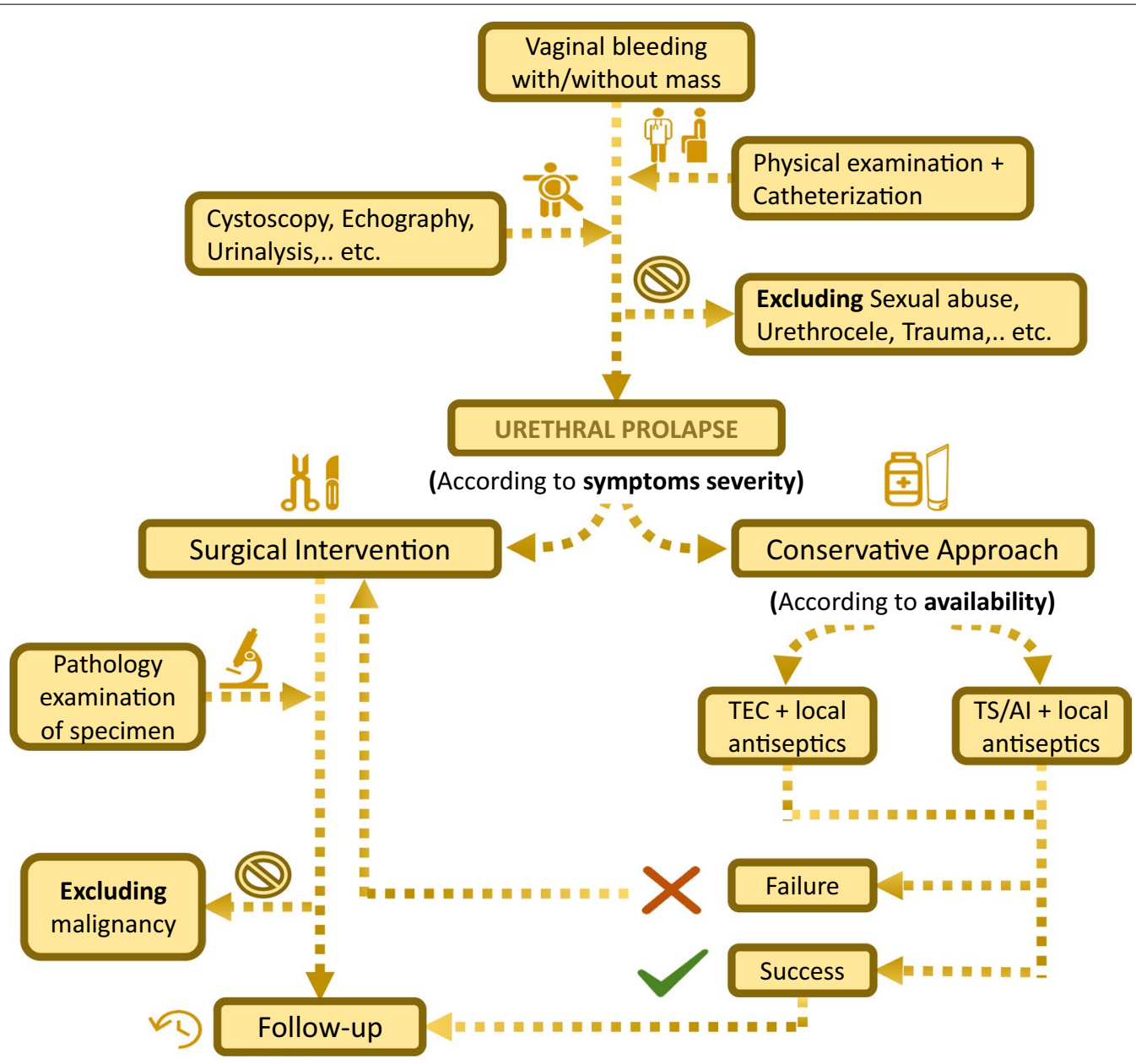

Fig. 5 Proposed algorithm for diagnosis and management of urethral prolapse in children

Urethral prolapse should be differentiated from other urethral lesions including urethral caruncles. They are the commonest benign tumors of female urethra presenting as fleshy outgrowths at the urethral meatus. However, they are usually postmenopausal and at the posterior lip [24].

The most common presenting symptoms include vaginal bleeding and vaginal mass $[4,19]$. Vaginal bleeding is presented in a broad spectrum of diseases, such as hormonal imbalance, urinary tract infections, and trauma which may or may not be associated with neoplasm, vulvovaginitis, urethral prolapse, and sexual abuse. Whenever sexual abuse is suspected, careful examination and interview with the parents should be taken.

Other causes of vaginal bleeding include urethral caruncle, hemorrhagic cystitis, hypothyroidism, precocious puberty, ovarian cyst presence, foreign body, exposure to exogenous sex steroids [2, 9]. In the case of urethral prolapse, the bleeding results from vascular congestion and edema of the prolapsed tissue that surrounds the urethral meatus [13]. The classical appearance of the 'doughnut' sign enables the diagnosis to be made easily on clinical grounds alone [8]. Occasionally, a catheter or instrument tip may be used to confirm that the opening lies at the center of the prolapsed tissue $[3,8]$.

The management of urethral prolapse continues to be controversial. However, our results showed clearly that conservative treatment can be the best option whenever there are mild symptoms. The non-surgical treatments consisted of topical estrogen cream, sitz bath, local antiseptic antibiotic, steroid cream, antispasmodic drugs to treat any underlying condition, or manipulative reduction. However, Ballouhey et al. [1] suggested that conservative management is suitable for non-symptomatic patients while surgical resection offers safe and cost-effective improvement and it remains the primary treatment strategy for patients with significant symptoms and the reference treatment. We believe that suitable management depends mainly on the clinical findings and the severity of the symptoms. 
Medical treatment was successful in 19\% of all patients and raised to $32.7 \%$ in the portion of children selected for the initial conservative approach, particularly patients with a mild degree of prolapse. Longterm follow-up is required as recurrence was reported up to 2 years following conservative treatment. Figure 5 schematically represents a diagnostic and treatment algorithm that can be used in practice to manage children with urethral prolapse. Future studies can compare surgical with conservative approaches as well as different medical treatment modalities such as TEC and TS to better deliver evidence-based care and frame strong practical guidelines.

\section{Conclusions}

Urethral prolapse is still a rare condition. Few case reports and case series were encountered for pediatric patients. Vaginal bleeding or mass were the most common presentations. There is a controversy whether to go to direct surgery or to try initially a conservative approach. However, our review showed promising results with the latter. In the interim, additional comparative studies are required to compare surgical versus conservative approaches and also to compare the use of estrogen versus corticosteroids as a local treatment when a conservative approach is selected.

\section{Abbreviations}

UP: Urethral prolapse; UTI: Urinary tract infection; TEC: Topical estrogen cream; TS: Topical steroids.

\section{Acknowledgments}

The authors are grateful to Ms. Marah Mansour for her support.

\section{Authors' contributions}

SEOK and MA contributed to design and concept, searching database, extracting and analyzing the data, making figures, and writing the manuscript. RN and MM contributed to screening records and extracting data. MM and AK contributed to patient care, and supervision. MSE contributed to critically revising, improving the content, and writing the manuscript. All authors read and approved the final version of the manuscript.

\section{Funding}

This work did not receive any funding.

\section{Availability of data and materials}

The data supporting this review are from previously reported studies that have been cited.

\section{Declarations}

Ethics approval and consent to participate

Not applicable.

\section{Consent for publication}

Written informed consent was obtained from the parents of the patient included in the study.

\section{Competing interests}

Prof Mohammed ElSheemy is a co-author of this study and the Editor-in-Chief of the journal. He declares a competing interest for this submission. He has not handled this manuscript. The rest of the authors have no conflict of interest to declare.

\section{Author details}

${ }^{1}$ Department of Medicine, Faculty of Medicine, University of Tlemcen, 13000 Tlemcen, Algeria. ${ }^{2}$ Faculty of Medicine, University of Aleppo, Aleppo, Syria. ${ }^{3}$ Department of Medicine, Faculty of Medicine, University of Oran 1, 31000 Oran, Algeria. ${ }^{4}$ Department of Pediatrics, Infant-Mother Hospital of Tlemcen, Tlemcen, Algeria. ${ }^{5}$ Urology Department, Kasr AlAiny School of Medicine, Cairo University, Cairo, Egypt.

Received: 18 May 2021 Accepted: 29 October 2021

Published online: 24 November 2021

References

1. Ballouhey Q, Galinier P, Gryn A, Grimaudo A, Pienkowski C, Fourcade L (2014) Benefits of primary surgical resection for symptomatic urethral prolapse in children. J Pediatr Urol 10(1):94-97. https://doi.org/10.1016/j. jpurol.2013.06.011

2. Aprile A, Ranzato C, Rizzotto MR, Arseni A, Da Dalt L, Facchin P (2011) "Vaginal" bleeding in prepubertal age: a rare scaring riddle, a case of the urethral prolapse and review of the literature. Forensic Sci Int 210(13):e16-20. https://doi.org/10.1016/j.forsciint.2011.04.017

3. Wei Y, Wu SD, Lin T, He DW, Li XL, Wei GH (2017) Diagnosis and treatment of urethral prolapse in children: 16 years' experience with 89 Chinese girls. Arab J Urol 15(3):248-253. https://doi.org/10.1016/j.aju.2017.03.004

4. McCaskill A, Inabinet CF, Tomlin K, Burgis J (2018) Prepubertal genital bleeding: examination and differential diagnosis in pediatric female patients. J Emerg Med 55(4):e97-100. https://doi.org/10.1016/j.jemermed. 2018.07.011

5. Hillyer S, Mooppan U, Kim H, Gulmi F (2009) Diagnosis and treatment of urethral prolapse in children: experience with 34 cases. Urology 73(5):1008-1011. https://doi.org/10.1016/j.urology.2008.10.063

6. Liu C, Lin Y, Chen X, Li S, Zhu H (2018) Urethral prolapse in prepubertal females: report of seven cases. J Obstet Gynaecol Res 44(1):175-178

7. Zhang J, Zhang B, Su Y, Guo S, Liu C, Bai J et al (2020) Prepubertal vaginal bleeding: an inpatient series from a single center in Fujian China. J Pediatr Adolesc Gynecol 33(2):120-124. https://doi.org/10.1016/j.jpag. 2019.11.009

8. Holbrook C, Misra D (2012) Surgical management of urethral prolapse in girls: 13 years' experience. BJU Int 110(1):132-134

9. Agarwal S, Lall A, Bianchi A, Dickson A (2008) Uro-genital bleeding in pre-menarcheal girls: dilemmas of child abuse. Pediatr Surg Int 24(6):745-746

10. Ekenze SO, Mbadiwe OM, Ezegwui HU (2009) Lower genital tract lesions requiring surgical intervention in girls: perspective from a developing country. J Paediatr Child Health 45(10):610-613

11. Da Silva-Anoma S, Dibi Bertin K, Ossenou O, Atafi Gaudens D, Yao D, Roux C (2001) Le prolapsus muqueux de l'urètre de la fillette en Côte-d'Ivoire. Ann Urol (Paris) 35(1):60-63

12. Fiogbe M, Hounnou G, Koura A, Agossou-Voyeme K (2011) Urethral mucosal prolapse in young girls: a report of nine cases in Cotonou. African J Paediatr Surg 8(1):12-14

13. Shurtleff BT, Barone JG (2002) Urethral prolapse: four quadrant excisional technique. J Pediatric Adolesc Gynecol 15:209-211

14. Lora A, Scrimin F, Taddio A, Ventura A, Barbi E (2017) A premenarcheal girl with urogenital bleeding. Arch Dis Child 102:472

15. Ballouhey Q, Abbo O, Sanson S, Cochet T, Galinier P, Pienkowski C (2013) Hémorragie génitale de la petite fille: penser au prolapsus urétral. Gynecol Obstet Fertil 41(6):404-406. https://doi.org/10.1016/j.gyobfe. 2013.04 .006

16. Vunda A, Vandertuin L, Gervaix A (2011) Urethral prolapse: an overlooked diagnosis of urogenital bleeding in pre-menarcheal girls. J Pediatr 158(4):682-683. https://doi.org/10.1016/j.jpeds.2010.11.050 
17. Pereira S, Mottaleb M, Subramanian G (2011) Genital bleeding. BMJ Case Rep 2010:1

18. McKenna EM, Humphrey MD (1999) Urethral prolapse in a 7-year-old girl. Aust New Zeal J Obstet Gynaecol 39(3):387-388

19. Kondamudi NP, Gupta A, Watkins A, Bertolotti A (2014) Prepubertal girl with vaginal bleeding. J Emerg Med 46(6):769-771. https://doi.org/10. 1016/j.jemermed.2013.11.075

20. Novoa-Carballal R, Cantero Rey R, García García I, Valenzuela BO (2019) Urethral prolapse: diagnostic image of a rare pathology. An Pediatr 91(3):212-213. https://doi.org/10.1016/j.anpedi.2018.08.002

21. Ninomiya T, Koga $H$ (2017) Clinical characteristics of urethral prolapse in Japanese children. Pediatr Int 59(5):578-582
22. Hill AJ, Siff L, Vasavada SP, Paraiso MFR (2016) Surgical excision of urethral prolapse. Int Urogynecol J 27(10):1601-1603

23. Schreiner $L$, Nygaard CC, Anschau F (2013) Urethral prolapse in premenopausal, healthy adult woman. Int Urogynecol J 24(2):353-354

24. Yakasai IA, Aji SA, Muhammed YA, Abubakar IS (2012) Unusual presentation of urethral carunle in a 2 year old child: a case report. Asian J Nat Appl Sci 1(4):22-26

\section{Publisher's Note}

Springer Nature remains neutral with regard to jurisdictional claims in published maps and institutional affiliations.

\section{Submit your manuscript to a SpringerOpen ${ }^{\circ}$ journal and benefit from:}

- Convenient online submission

- Rigorous peer review

- Open access: articles freely available online

- High visibility within the field

- Retaining the copyright to your article

Submit your next manuscript at $\boldsymbol{\nabla}$ springeropen.com 